\title{
A practical method for use in epidemiological studies on enamel hypomineralisation
}

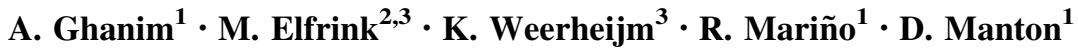

Received: 14 December 2014 / Accepted: 27 February 2015/Published online: 28 April 2015

(C) European Academy of Paediatric Dentistry 2015

\begin{abstract}
With the development of the European Academy of Paediatric Dentistry (EAPD) judgment criteria, there has been increasing interest worldwide in investigation of the prevalence of demarcated opacities in tooth enamel substance, known as molar-incisor hypomineralisation (MIH). However, the lack of a standardised system for the purpose of recording $\mathrm{MIH}$ data in epidemiological surveys has contributed greatly to the wide variations in the reported prevalence between studies. The present publication describes the rationale, development, and content of a scoring method for MIH diagnosis in epidemiological studies as well as clinic- and hospitalbased studies. The proposed grading method allows separate classification of demarcated hypomineralisation lesions and other enamel defects identical to MIH. It yields an informative description of the severity of MIH-affected
\end{abstract}

A. Ghanim

dentagh@gmail.com

M. Elfrink

marlies@paediatricresearchproject.nl

K. Weerheijm

weerkamp@xs4all.nl

R. Mariño

marino@unimelb.edu.au

D. Manton

djmanton@unimelb.edu.au

1 Oral Health Cooperative Research Centre, Melbourne Dental School, The University of Melbourne, Melbourne, VIC 3010, Australia

2 Paediatric dentist Mondzorgcentrum, Amsterdam, The Netherlands

3 Paediatric Research Project (PREP), Amsterdam, The Netherlands teeth in terms of the stage of visible enamel destruction and the area of tooth surface affected (i.e. lesion clinical status and extent, respectively). In order to preserve the maximum amount of information from a clinical examination consistent with the need to permit direct comparisons between prevalence studies, two forms of the charting are proposed, a short form for simple screening surveys and a long form desirable for prospective, longitudinal observational research where aetiological factors in demarcated lesions are to be investigated in tandem with lesions distribution. Validation of the grading method is required, and its reliability and usefulness need to be tested in different age groups and different populations.

Keywords EAPD $\cdot$ MIH $\cdot$ HSPM $\cdot$ Molar-incisor hypomineralisation - Hypomineralised second primary molar $\cdot$ Enamel hypomineralisation $\cdot$ Epidemiological studies

\section{Introduction}

In the recent past, non-fluoride-associated developmental defects of tooth enamel have been described with a host of terms such as: mottled enamel, non-endemic mottling of enamel, internal enamel hypoplasia, cheese molars, nonfluoride enamel opacities, opaque spots, and idiopathic enamel opacities (Weerheijm et al. 2001). Much of this developmentally defective enamel would currently be identified as molar-incisor hypomineralisation (MIH). The term MIH was introduced in 2001 to describe demarcated, qualitative developmental defects of enamel, affecting one or more first permanent molars, with or without involvement of the incisor teeth, where individuals with affected permanent incisors are not assigned as having MIH unless 
associated with demarcated lesions in at least one of the first permanent molars (Weerheijm et al. 2001). The given term represents an endeavour to unify research and help to build up a sound knowledge of the condition by clinicians. Researchers introduced the term molar hypomineralisation (MH), as a subset of MIH (Chawla et al. 2008; Mangum et al. 2010; Oliver et al. 2014; The $\mathrm{D}_{3} \mathrm{G}$ website 2014). Although the first permanent molars are the most commonly and severely affected hypomineralised teeth, these molars are incorporated in the definition of MIH. Further to this, due to the temporal association in coronal mineralisation of the second primary molar with that of the first permanent molar and incisors, diagnosis of MIH-like opacities in the second primary molars (SPM) affecting one to four second primary molars affects up to $9 \%$ of SPM and has been denominated as hypomineralised second primary molar (HSPM) (Elfrink et al. 2008, 2012; Ghanim et al. 2013a).

MIH defects can influence the general health and quality of life of an affected child, and its treatment is often challenging to both the patient and clinician (Jälevik and Klingberg 2012). Affected teeth often develop advanced carious lesions and, therefore, require substantial restorative care and repeated treatments (Leppäniemi et al. 2001; Ghanim et al. 2013b). Views of the oral healthcare providers from the European, Australian, New Zealand, Southeast Asian, and Middle Eastern regions indicate that the clinical effect of MIH is increasing and poses a costly burden for public health (Weerheijm and Mejàre 2003; Crombie et al. 2008; Ghanim et al. 2011a; Bagheri et al. 2014; Hussein et al. 2014).

For patients and dental practitioners to apply appropriate measures to limit the effect of MIH and for policy makers to have a reliable picture of the defect characteristics in a specific population, the dynamics of MIH should be reflected in its assessment systems. A clinical evaluation guide for MIH based on scientific criteria was formulated and named the European Academy of Paediatric Dentistry (EAPD) judgment criteria (Weerheijm et al. 2003). Although the established criteria were used extensively, prevalence rates of $\mathrm{MIH}$ reported in epidemiological studies still differ considerably. This could be an actual difference secondary to socio-behavioural, environmental, and genetic factors of the studied populations; on the other hand, it drives advocacy for the conduct of further studies with more standardised protocols and study design (Elfrink et al. 2015).

Recently, a workshop on MIH was held in association with the 12th EAPD Congress in Sopot, Poland, 2014. Pitfalls of the available scholarly literature regarding $\mathrm{MIH}$ epidemiology were reiterated, and suggestions were given to underpin and broaden the scope of future research and to enhance the optimal use of the established EAPD guidelines for MIH data in epidemiological surveys. A consensus reached by the workshop experts and participants was that there is a need to develop a data collection instrument for summarising clinical data gleaned from field examinations (Elfrink et al. 2015). Consequently, in the present manuscript, we propose that unified, practical scoring forms for the classification and diagnosis of MIH in clinical practice as well as epidemiological surveys should be used. The scoring sheets classify MIH defects on the basis of their clinical visual appearance. Ideally, the charting forms aim to achieve maximum data recording whilst remaining sensitive to the severity of the defect, where severity is represented by both the stage of visible enamel destruction and the amount of tooth surface area affected (i.e. lesion clinical status and extent, correspondingly), and would be most suitable for longitudinal as well as cross-sectional epidemiological and clinic-based studies.

\section{Description of the proposed charting method}

The proposed charting method integrates the elements of the EAPD criteria and the modified index of developmental defects of enamel (mDDE index) for grading the clinical status of MIH and its extent on the involved tooth surface as well as other enamel defects. In order to take into account the varied needs and objectives of studies, two forms of the chart are proposed, a short form for simple screening surveys and a longer form for more detailed, communitybased or clinic-based studies. In both forms, EAPD criteria emerged as the key elements reflecting the theme of charting. The short data set form is designed to grade only index teeth which have been mentioned in the definition of MIH and HSPM, namely first permanent molars, permanent incisors, and second primary molars (hereafter termed FPM, PI, and SPM, respectively).

Due to the available evidence on the involvement of other teeth with demarcated hypomineralisation defects (Suckling et al. 1989; Kukleva et al. 2008; Soviero et al. 2009; Seow et al. 2011; Leen 2013), the long data set form is formulated to diagnose all teeth at surface level available at the time of the dental examination in addition to MIH/ HSPM-specific index teeth. However, the terms MIH and HSPM should not be applied to teeth other than FPM and PIs, and SPM, respectively. The following sections describe, in detail, definitions of terms used in the charting format, differential diagnosis of $\mathrm{MIH}$ from other enamel lesions, grading criteria and special considerations to be taken into account for the purpose of charting. 


\section{Definition of non-MIH/HSPM enamel lesions used in the charting forms}

Diffuse opacity A defect involving an alteration in the translucency of the enamel, variable in degree. The defective enamel is of normal thickness, at eruption, has a relatively smooth surface and is white in colour. It can have a linear, patchy or confluent distribution, but there is no clear boundary with the adjacent normal enamel (Federation Dentaire International (FDI) 1992).

Hypoplasia A defect involving the surface of the enamel and associated with a reduced localised thickness of enamel. It can occur according to the analysis described by Federation Dentaire International (FDI) published in 1992 as:

- Pits: tiny areas of enamel loss, which could be single, multiple, shallow or deep, scattered or in rows.

- Grooves/linear: single or multiple, narrow or wide (maximum $2 \mathrm{~mm}$ ) grooves of enamel loss.

- Area: partial or complete absence of enamel over a considerable area of a tooth crown.

Amelogenesis imperfecta (AI) Refers to a range of enamel malformations, genomic in origin, and include variations in thickness (hypoplasia), smoothness and hardness (hypocalcification and hypomaturation), or a combination of these (Crawford and Aldred 2007).

Hypomineralisation defect (non-MIH/HSPM) Includes MIH/HSPM-like demarcated defects diagnosed in primary or permanent teeth other than MIH/HSPM index teeth, where the timing of their coronal mineralisation is not concomitant with that of the index teeth or the source of demarcated hypomineralisation could be due to local causes rather than aetiological factors of systemic origin [e.g. trauma and infection of the primary predecessors (Lo et al. 2003; Broadbent et al. 2005)].

A developmental defect known as Turner's tooth is an example for this category; it shows variable appearance that can be seen as a mixture of change in appearance and loss of enamel substance in permanent teeth and usually affects only one tooth in the dentition, mainly premolar teeth (secondary to infected primary molars) and permanent central incisors (secondary to injury to the primary incisors) (Broadbent et al. 2005; Geetha Priya et al. 2010) (Fig. 1). On the other hand, permanent canines may exhibit demarcated lesions consistent with the clinical appearance of $\mathrm{MIH}$ at their tips as mineralisation of this area occurs at a similar time to that of permanent index teethy. However, the defect could be still due to periapical inflammation in their predecessors and canines have not been included in the established MIH definition; hence, it should be classified under non-MIH/HSPM hypomineralisation defect.

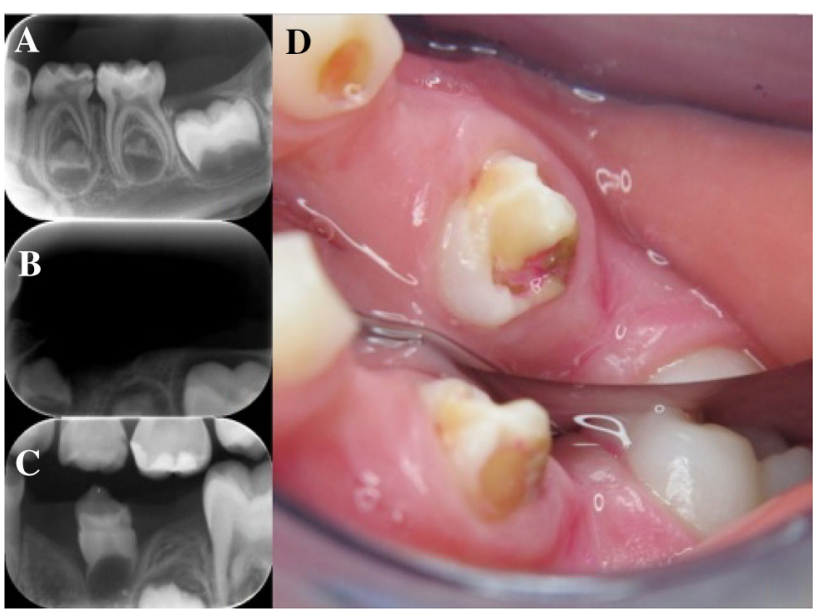

Fig. 1 Radiographical and clinical images showing malformed crown of mandibular left first premolar (Turner's tooth). Photo courtesy of Weerheijm $\mathrm{K}$ and Elfrink $\mathrm{M}$

\section{Differential diagnosis}

With regard to the above-mentioned definitions, differential diagnosis of demarcated hypomineralisation lesions from other enamel defects that occur during amelogenesis is essential to avoid misdiagnosis and ensure best management of individuals with MIH. In contrast to diffuse opacities, intact hypomineralised defects in MIH are demarcated opacities that have clear borders with apparently sound enamel unlike the irregular, diffuse hypomineralisation observed in fluorosis. Demarcated opacities usually occur in isolated teeth and are relatively caries prone, whilst diffuse opacities may affect all teeth with bilateral symmetry and the structure of the enamel is relatively caries resistant.

Hypoplasia, alternatively, may be difficult to distinguish from lost enamel substance resulting from MIH, mainly when hypomineralisation exists with the hypoplastic lesions. Nevertheless, in hypoplasia, the borders to the normal enamel are mostly regular and smooth, whereas in MIH-associated-enamel substance loss, the enamel edges are sharp and irregular where the enamel has chipped off. The use of a periodontal probe can help to confirm the visual assessment by running it gently across the margins of the defect.

Differentiating AI and MIH, can be difficult in severe MIH cases, where the molars are equally affected and mimic the appearance of AI. Nonetheless, in MIH, the appearance of the defects is more asymmetrical, whilst in AI, all permanent and primary teeth tend to be affected (i.e. generalised involvement). There are specific characteristics pertaining to individual presentations of AI, such as taurodontic molars or an anterior open bite. Moreover, family history and history of systemic disorders/illnesses are still 
crucial discriminative factors (Weerheijm 2004; Crawford and Aldred 2007).

Further to this, carious white spot lesions may occasionally be mistaken for demarcated enamel lesions. The actual distinction between them can be made possibly on the basis of their definitions. A white spot lesion represents the early clinical stages of dental caries. It is marked by having a chalky, opaque appearance and irregular surface. The initial carious lesions on smooth surfaces are found where plaque accumulates, close to contact areas adjacent to the cervical margins of the tooth, and around the gingival margins, areas where enamel hypomineralisation rarely occurs (Seow 1997).

\section{Recording criteria and charting forms}

The charting format comprises two main sections associated with the assessment of the visual clinical presentation of enamel lesions (clinical status criteria) and the size of the tooth surface area affected by the lesion (lesion extension criteria), and a minor section concerned with tooth eruption status (eruption status criteria). Tables 1 and 2 show short and long formats of the charting sheet. The diagram illustrated in Fig. 2 will assist the examiner in deciding on the appropriate coding of MIH/HSPM and other enamel defects.

Table 1 MIH/HSPM clinical data recording sheet—first permanent molars, permanent incisors, and second primary molars (short form)

\footnotetext{
Examination Date
}

Subject's ID Subject's Name

MAXILLA LEFT

MAXILLA RIGHT 11

\begin{tabular}{|c|c|c|c|c|c|c|c|c|} 
& 16 & 55 & 12 & 11 & 21 & 22 & 65 & 26 \\
\hline Tooth & & & & & & & & \\
\hline
\end{tabular}

MANDIBLE RIGHT

MANDIBLE LEFT

\begin{tabular}{|c|c|c|c|c|c|c|c|c|}
\cline { 6 - 10 } & 46 & 85 & 42 & 41 & 31 & 32 & 75 & 36 \\
\hline Tooth & & & & & & & & \\
\hline
\end{tabular}

Charting Criteria
Eruption status criteria
$\begin{aligned} & \text { A }=\text { not visible or less than } 1 / 3 \text { of the occlusal surface or of the crown } \\ & \text { length of incisor is visible. }\end{aligned}$
Clinical status criteria
$\begin{aligned} & 0=\text { No visible enamel defect. } \\ & 1=\text { Enamel defect, non-MIH/HSPM. } \\ & 2=\text { White, creamy demarcated, yellow or brown demarcated opacities. } \\ & 3=\text { Post-eruptive enamel breakdown (PEB). } \\ & 4=\text { Atypical restoration. } \\ & 5=\text { Atypical caries. } \\ & 6=\text { Missing due to MIH/HSPM. } \\ & 7=\text { Cannot be scored*. }\end{aligned}$

Lesion extension criteria (only after diagnosing MIH/HSPM, i.e. scores 2 to 6 )

I = less than one third of the tooth affected.

II $=$ at least one third but less than two thirds of the tooth affected.

III $=$ at least two thirds of the tooth affected.
Notes

Score a tooth on MIH/HSPM if at least $1 / 3$ or more of the tooth is visible, otherwise, use Code $\mathrm{A}$ and no need to score the clinical status or the extent.

Record the clinical status first and lesion extent as second (if required). Use punctuation mark "," to separate between digits.

An enamel defect of one millimetre or less in diameter is considered as sound.

If non MIH/HSPM lesions diagnosed together with MIH/HSPM, score the non MIH/HSPM first.

When uncertainty exists regarding rating of the lesion the less severe rating is to be recorded.

When more than one MIH/HSPM lesion exists per tooth, visually combine all areas affected by the lesion and score the more severe presentation.

*Index tooth with extensive coronal breakdown and where the potential cause of breakdown is impossible to determine. 
Table 2 MIH/HSPM clinical data recording sheet-permanent and primary dentitions (long form)

Examination Date

Subject's IID Subject's Name

Age

$\mathrm{DOB}$ Gender

\begin{tabular}{|c|c|c|c|c|c|c|c|c|c|c|c|c|c|c|}
\hline \multirow[b]{2}{*}{ Surface } & \multicolumn{2}{|c|}{ MAXILLA RIGHT } & 55 & 54 & 53 & 52 & 51 & 61 & 62 & 63 & 64 & 65 & \multicolumn{2}{|c|}{ MAXILLA LEFT } \\
\hline & 17 & 16 & 15 & 14 & 13 & 12 & 11 & 21 & 22 & 23 & 24 & 25 & 26 & 27 \\
\hline Buccal (labia & & & & & & & & & & & & & & \\
\hline Occlusal (incis & & & & & & & & & & & & & & \\
\hline Palatal & & & & & & & & & & & & & & \\
\hline
\end{tabular}

\begin{tabular}{|c|c|c|c|c|c|c|c|c|c|c|c|c|c|c|}
\hline \multirow[b]{2}{*}{ Surface } & \multicolumn{2}{|c|}{ MANDIBLE RIGHT } & 85 & 84 & 83 & 82 & 81 & 71 & 72 & 73 & 74 & 75 & \multicolumn{2}{|c|}{ MANDIBLE LEFT } \\
\hline & 47 & 46 & 45 & 44 & 43 & 42 & 41 & 31 & 32 & 33 & 34 & 35 & 36 & 37 \\
\hline Buccal (labia & & & & & & & & & & & & & & \\
\hline Occlusal (incis & & & & & & & & & & & & & & \\
\hline Lingual & & & & & & & & & & & & & & \\
\hline
\end{tabular}

\section{Charting Criteria}

\section{Eruption status criteria}

$A=$ not visible or less than $1 / 3$ of the occlusal surface or of the crown length of incisor is visible.

\section{Clinical status criteria}

$0=$ No visible enamel defect.

$1=$ Enamel defect, non-MIH/HSPM

$11=$ diffuse opacities

$12=$ hypoplasia

$13=$ amelogenesis imperfecta

$14=$ hypomineralisation defect (not MIH/HSPM)

$2=$ demarcated opacities

$21=$ White or creamy demarcated opacities

$22=$ Yellow or brown demarcated opacities

$3=$ Post-eruptive enamel breakdown (PEB)

$4=$ Atypical restoration

$5=$ Atypical caries

$6=$ Missing due to MIH/HSPM

$7=$ Cannot be scored*

Lesion extension criteria (only after diagnosing MIH/HSPM, i.e. scores 2 to 6 )

$I=$ less than one third of the tooth surface affected.

$\mathrm{II}=$ at least one third but less than two thirds of the surface affected.

III $=$ at least two thirds of the tooth surface affected.
Notes

Score a tooth surface on MIH/HSPM if at least $1 / 3$ or more of the tooth surface is visible, otherwise, use Code A and no need to score the clinical status or the extent.

In the charting sheet place a circle around the tooth number you score.

Record the clinical status first and lesion extent as second (if required). Use punctuation mark "," to separate between digits.

An enamel defect of one millimetre or less in diameter is considered as sound.

Use codes 2 to 6 for MIH/HSPM index teeth only (i.e. FPM, PIs and SPM). Codes $(0,11,12,13)$ are applicable on all teeth including index teeth. Code 14 should be assigned to any tooth other than index teeth when MIH/HSPM-like opacities are diagnosed.

If non MIH/HSPM lesions diagnosed together with MIH/HSPM, score the non MIH/HSPM first.

When uncertainty exists regarding rating of the lesion the less severe rating is to be recorded.

When more than one MIH/HSPM lesion exists per surface, visually combine all areas affected by the lesion and score the more severe presentation.

For MIH/HSPM lesion involving the incisal surface only, score the labio-incisal (labial) and palato/lingual-incisal (palatal/lingual) surfaces as normal and assign the incisal surface the most severe score.

If the main code is not to be chosen then there is no need to look at the sub-codes that belong to that main code, the examiner can proceed to the next main code.

*Index tooth with extensive coronal breakdown and where the potential cause of breakdown is impossible to determine. 
Recording criteria per eruption status (eruption status criteria)

Unerupted or partially erupted (code A) Not visible or less than $1 / 3$ of the occlusal surface or of the crown length of incisor is visible. Otherwise, the tooth/tooth surface is considered as: Fully erupted/almost fully erupted Fully erupted or at least $1 / 3$ but less than the total occlusal surface erupted and/or less than the total crown length of the incisor visible.

Recording criteria per clinical presentation (clinical status criteria)

Summary of the definitions and scores for both short and long forms are elucidated in Table 3.

Fig. 2 Flow chart demonstrating the recommended sequence for diagnosis of MIH/HSPM and other enamel defects
Recording criteria per MIH/HSPM lesion extent (lesion extension criteria)

The extent of the defect in a tooth is measured by the surface area of the enamel affected as follows: code I: less than $1 / 3$ of the tooth surface involved; code $I I$ : at least $1 / 3$ but less than $2 / 3$ of the tooth surface involved; code III: at least $2 / 3$ of the tooth surface involved. The total area affected is to be related to the total visible tooth surface area.

\section{Notes on the recording and coding of data}

The following considerations are applicable on both short and long data set sheets. Table 4 describes further

Can the tooth/tooth surface be scored?

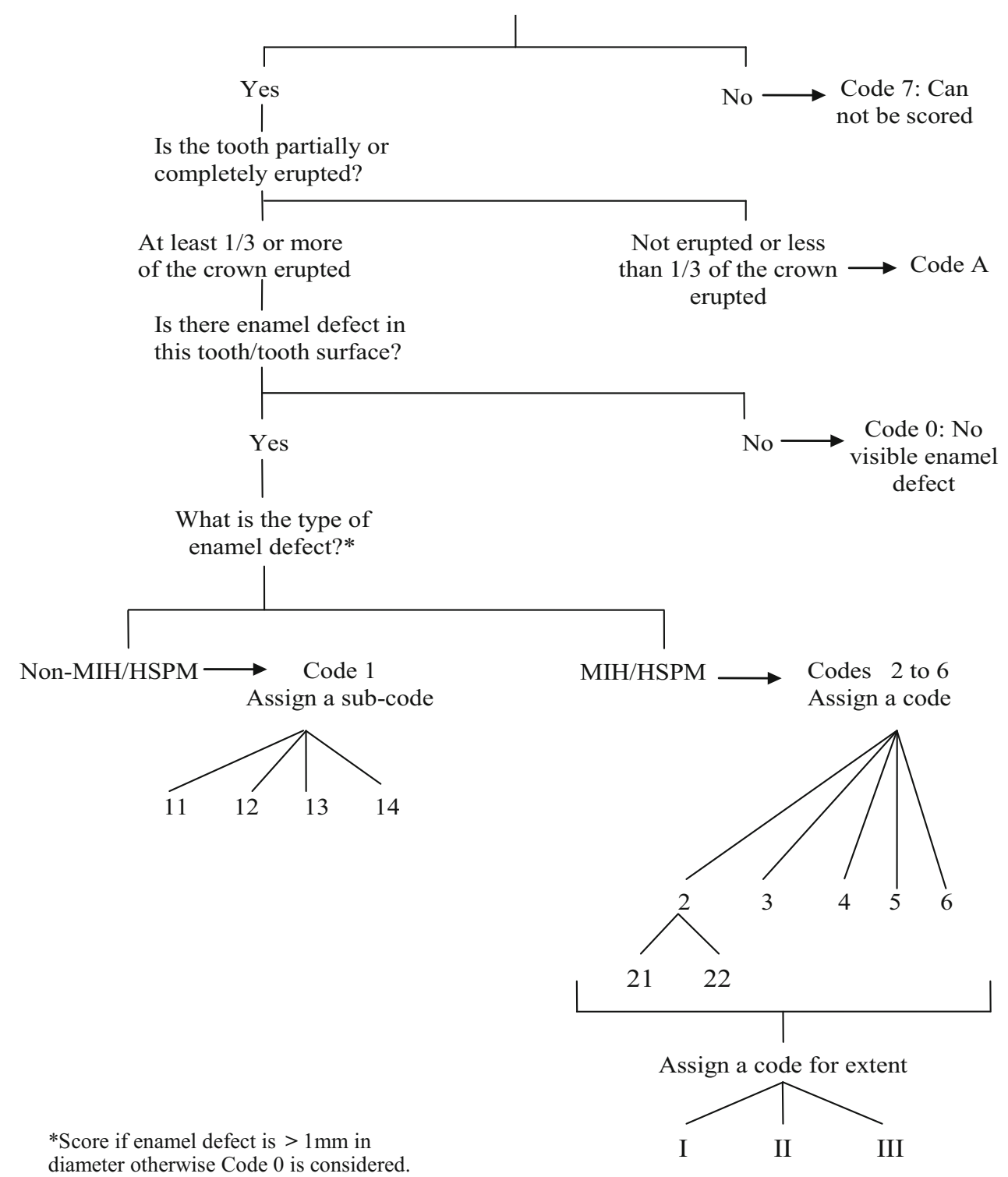


Table 3 Codes and definitions of the clinical status of enamel defects for the short and long data set forms

\begin{tabular}{|c|c|}
\hline Code & Definition \\
\hline $\mathbf{0}$ & $\begin{array}{l}\text { No visible enamel defect: Tooth/surface is apparently free of enamel lesions represented by diffuse } \\
\text { opacities, hypoplasia, demarcated hypomineralisation and amelogenesis imperfecta. }\end{array}$ \\
\hline 1 & $\begin{array}{l}\text { Enamel defect, non-MIH/HSPM: Quantitative or qualitative defects that are not comply with the } \\
\text { characteristic features mentioned in the MIH/HSPM definitions. These defects include the following; }\end{array}$ \\
\hline 11 & $\begin{array}{l}\text { Diffuse opacities: These defects can have a linear, patchy or patchy confluent distribution with } \\
\text { indistinct borders with the surrounding normal enamel exists. Also includes opacities due to fluorosis. }\end{array}$ \\
\hline 12 & $\begin{array}{l}\text { Hypoplasia: Defect can present as pit, groove and areas of partial or total enamel missing with rounded } \\
\text { smooth borders adjacent to the intact enamel. }\end{array}$ \\
\hline 13 & $\begin{array}{l}\text { Amelogenesis imperfect: Includes a range of enamel malformations, genomic in origin, and include } \\
\text { variations in thickness (hypoplastic malformation), smoothness and hardness (hypocalcified and } \\
\text { hypomatured malformation) or a combination of these. }\end{array}$ \\
\hline 14 & $\begin{array}{l}\text { Hypomineralisation defect (not MIH/HSPM): Includes MIH/HSPM-like demarcated defects } \\
\text { diagnosed in primary or permanent teeth other than MIH/HSPM index teeth. }\end{array}$ \\
\hline 2 & $\begin{array}{l}\text { Demarcated opacities: A demarcated defect involving an alteration in the translucency of the enamel, } \\
\text { variable in degree from white/creamy to yellow/brown in colour. The defective enamel is of normal } \\
\text { thickness with a smooth surface and a clear defined boundary from adjacent, apparently sound, enamel. }\end{array}$ \\
\hline 21 & White or creamy opacities: Demarcated opacity, white or creamy in colour. \\
\hline 22 & Yellow or brown opacities: Demarcated opacity yellow or brown in colour. \\
\hline 3 & $\begin{array}{l}\text { Post-eruptive enamel breakdown (PEB): Is a defect that indicates loss of initially formed surface } \\
\text { enamel subsequent to tooth eruption that it appears clinically as if the enamel has not formed at all. The } \\
\text { loss is often associated with a pre-existing demarcated opacity. PEB exists on surfaces traditionally } \\
\text { considered at low caries risk (i.e. cuspal ridges and smooth surfaces) and its areas are rough and have } \\
\text { uneven margins. }\end{array}$ \\
\hline 4 & $\begin{array}{l}\text { Atypical restorations: The size and shape of restorations do not conform to the usual picture of plaque } \\
\text { related caries. In most cases in posterior teeth there will be restorations extended to the buccal or palatal } \\
\text { smooth surfaces. The restorations may have residual affected enamel visible at the margins. In anterior } \\
\text { teeth the buccal restoration is not related to trauma. It is often seen in otherwise caries-free mouths. }\end{array}$ \\
\hline 5 & $\begin{array}{l}\text { Atypical caries: The size and form of the caries lesion do not match the present caries distribution in the } \\
\text { patient's mouth. The unusual pattern of caries can be further confirmed as associated to MIH/HSPM if } \\
\text { signs of MIH/HSPM are seen in other teeth in the same mouth. }\end{array}$ \\
\hline 6 & $\begin{array}{l}\text { Atypical extraction (Missing due to MIH/HSPM): Suspect when absence of a FPM or SPM in an } \\
\text { otherwise sound dentition and associated with opacities, PEB, atypical restorations or atypical caries in } \\
\text { at least one of the FPM or SPM. It is unlikely that PIs will be extracted due to MIH. }\end{array}$ \\
\hline 7 & $\begin{array}{l}\text { Cannot be scored: Index tooth with extensive coronal breakdown and where the potential cause of } \\
\text { breakdown is impossible to determine. }\end{array}$ \\
\hline
\end{tabular}

Codes and definitions marked in gray are related to the long form sheet only. instructions in question/answer format to be considered individually for each data set sheet.

- A child is deemed to have MIH/HSPM when at least one FPM or one SPM is diagnosed with MIH/HSPM.

- Individuals with affected PIs cannot be assigned as having MIH unless associated with demarcated lesions in at least one of the FPMs.

- Only score a tooth/tooth surface if $1 / 3$ or more of the tooth/tooth surface is visible. Otherwise, indicate it as code A and no need to proceed with the codes for the clinical status and the extent.

- An enamel defect of one millimetre or less in diameter is considered as sound.

- If the examiner is in doubt that the enamel is defective or falls within the range of normal, the tooth/tooth surface should be scored as defect-free.

- Similarly, when uncertainty exists regarding rating MIH/HSPM lesion severity (i.e. clinical status and extent), the less severe rating is to be recorded. 
Table 4 Long and short charting forms: individual considerations

\begin{tabular}{|c|c|c|}
\hline Question & Short charting form & Long charting form \\
\hline What tooth should be scored? & $\begin{array}{l}\text { Confine scoring to MIH/HSPM index teeth only (i.e. } \\
\text { FPMs, PIs, and SPMs) }\end{array}$ & $\begin{array}{l}\text { Include all teeth present in the mouth at the time of the } \\
\text { examination }\end{array}$ \\
\hline $\begin{array}{l}\text { Should scoring be on tooth } \\
\text { level or surface level? }\end{array}$ & $\begin{array}{l}\text { Scoring is made on tooth level. Inspect three surfaces } \\
\text { (buccal/labial, lingual/palatal, and occlusal/incisal) } \\
\text { and score the most severe lesion as a tooth score }\end{array}$ & $\begin{array}{l}\text { Scoring is made on surface level. For each tooth, } \\
\text { examine three surfaces (buccal/labial, } \\
\text { lingual/palatal, and occlusal/incisal) and score them } \\
\text { separately }\end{array}$ \\
\hline $\begin{array}{l}\text { When two different teeth } \\
\text { occupy the same space, } \\
\text { which tooth should be } \\
\text { scored? }\end{array}$ & Not applicable & $\begin{array}{l}\text { When both a primary and permanent tooth occupy the } \\
\text { same space, only the permanent tooth is coded }\end{array}$ \\
\hline $\begin{array}{l}\text { How would an incisal edge be } \\
\text { scored? }\end{array}$ & Not applicable & $\begin{array}{l}\text { For MIH/HSPM lesions involving incisal surfaces, it } \\
\text { is uncommon to see the incisal edge only involved; } \\
\text { therefore, score the labio-incisal (labial) and palato/ } \\
\text { lingual-incisal (palatal/lingual) surfaces as normal } \\
\text { and assign the incisal surface the most severe score }\end{array}$ \\
\hline $\begin{array}{l}\text { Should colour of demarcated } \\
\text { opacities be scored? }\end{array}$ & $\begin{array}{l}\text { No need to assign the colour of the opacity. Only write } \\
\text { code } 2 \text {. }\end{array}$ & $\begin{array}{l}\text { Assign colour of the opacity either as creamy/white or } \\
\text { as yellow/brown (codes } 21 \text { or } 22 \text {, respectively). }\end{array}$ \\
\hline $\begin{array}{l}\text { Which enamel defect is to } \\
\text { score? }\end{array}$ & $\begin{array}{l}\text { All enamel defects other than MIH/HSPM are } \\
\text { combined in one group and given code } 1\end{array}$ & $\begin{array}{l}\text { Split into main groups either as diffuse opacities, } \\
\text { hypoplasia, AI, or non-MIH/HSPM } \\
\text { hypomineralisation defect. (codes } 11 ; 12 ; 13 ; 14 \text {, } \\
\text { respectively). No detailed description per group is } \\
\text { required }\end{array}$ \\
\hline $\begin{array}{l}\text { How lesion extent should be } \\
\text { scored? }\end{array}$ & Extent of the lesion is scored on tooth level & Extent of the lesion is scored on surface level \\
\hline $\begin{array}{l}\text { How do I know which tooth I } \\
\text { scored? }\end{array}$ & Not applicable & $\begin{array}{l}\text { In the charting sheet, place a circle around the tooth } \\
\text { number you score }\end{array}$ \\
\hline $\begin{array}{l}\text { Which teeth should be } \\
\text { assigned the principal codes? }\end{array}$ & Not applicable & $\begin{array}{l}\text { Clinical status criteria: codes } 2-6 \text { to be used for MIH/ } \\
\text { HSPM index teeth only (i.e. FPM, PIs, and SPM). } \\
\text { Code } 14 \text { should be assigned to any tooth other than } \\
\text { index teeth when MIH/HSPM-like opacities are } \\
\text { diagnosed. Codes }(0,11,12,13) \text { are applicable on } \\
\text { both index and non index teeth }\end{array}$ \\
\hline
\end{tabular}

- When more than one MIH/HSPM lesion exists per tooth (for example, creamy and brown opacities), the more severe rating is to be recorded.

- If MIH/HSPM is diagnosed, all surfaces restored with full coverage should be coded as atypical restoration.

- Assign post-eruptive enamel breakdown (PEB) (code 3) in instances where atypical restoration has been lost and no carious cavities exist.

- Other causes of absence of a MIH/HSPM index tooth including congenitally missing, traumatic injury, extraction due to orthodontic reasons, due to dental caries as a primary cause, or due to normal exfoliation (for the SPM) should not be considered as missing due to MIH/HSPM.

- Lesion extent: record extent for MIH/HSPM lesions only. When more than one MIH/HSPM lesion exists per tooth or per surface, visually combine all areas affected by the lesion.

- Sequence of recording: the clinical status code first and lesion extent second (if required). Use punctuation mark "," to separate between digits. For example, an index tooth more than $1 / 3$ erupted which also exhibits white creamy opacities that cover less than $1 / 3$ of the tooth surface is scored as: (short form charting: 2, I); (long form charting: 21, I). If non-MIH/HSPM lesions diagnosed together with MIH/HSPM, score the nonMIH/HSPM first. For example, a completely erupted index tooth which presented with diffuse opacities and yellow brown demarcated opacities which cover more than two-thirds of a tooth surface is scored as (short form charting: 1, 2, III); (long form charting: 11, 22, III).

Figure 3 illustrates clinical examples of the different visual presentations of demarcated hypomineralised lesions in MIH/HSPM index teeth and other teeth. The figure also includes other enamel defects in order to help the examiners to distinguish between MIH/HSPM and other enamel disturbances. 


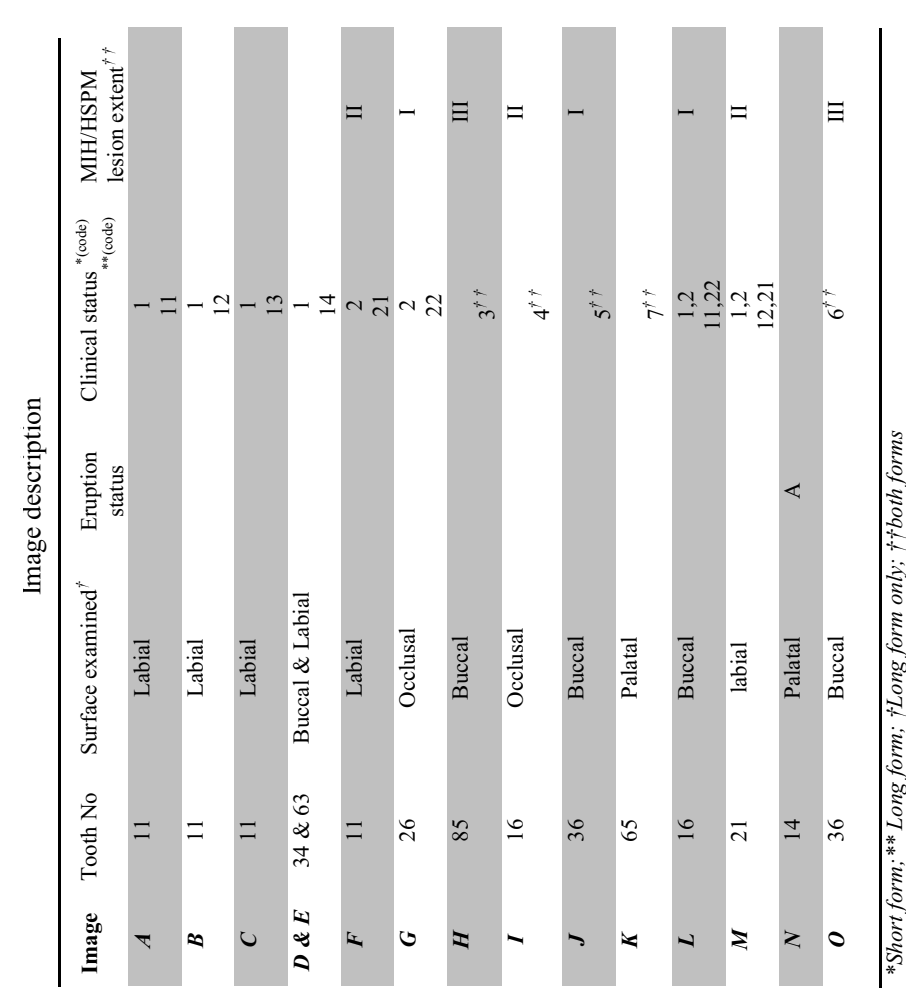

प
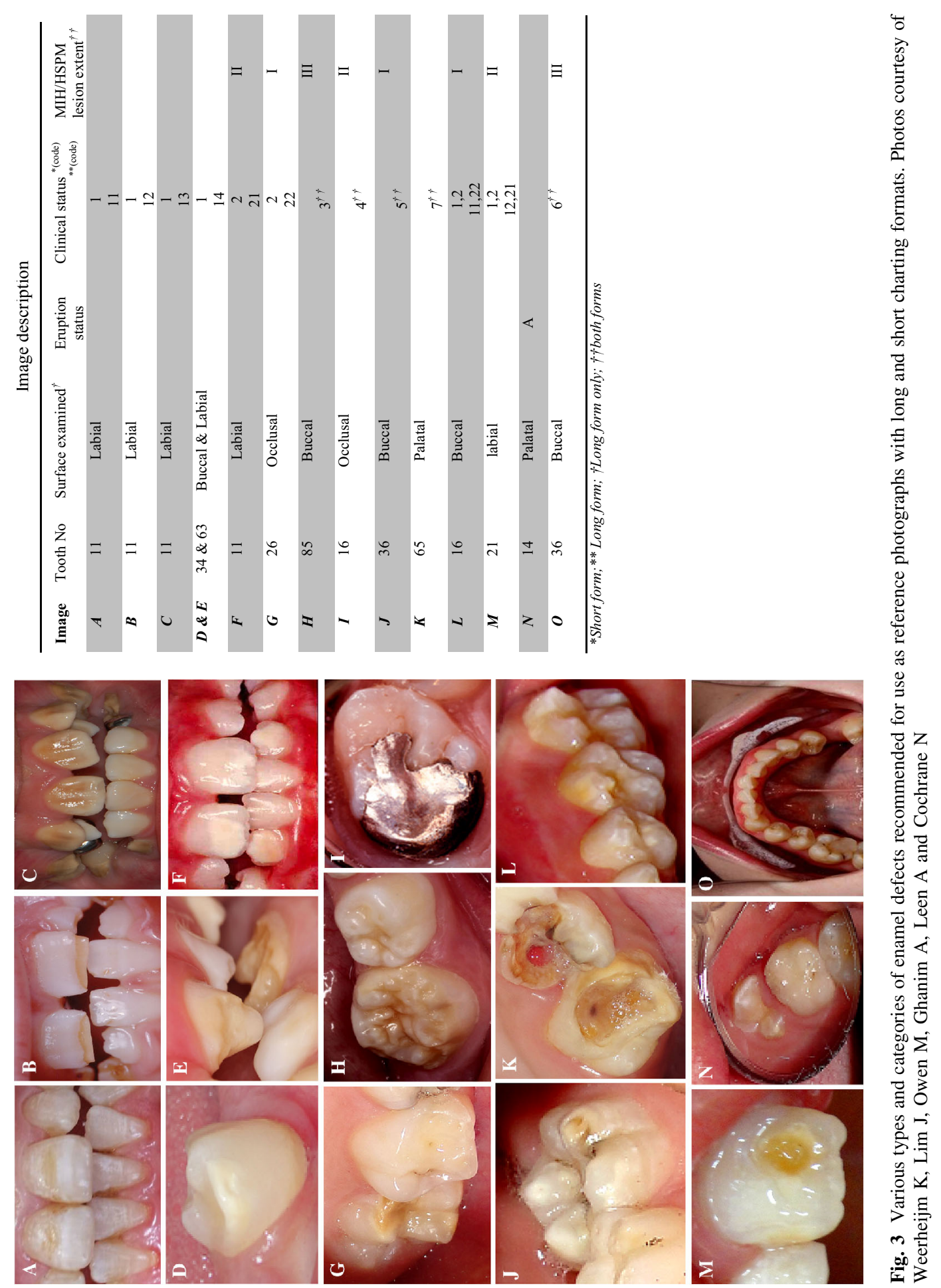


\section{Discussion}

As has been the case with research on dental caries, periodontal disease, and recently with dental erosion, the accumulation of a body of epidemiological data from different populations might provide new insights into the factors influencing the trends in the prevalence of $\mathrm{MIH}$. This is only possible, however, if the data are collected and reported using methods which are sufficiently similar to allow direct and valid comparison between the populations studied. The concept behind the proposed charting method is to lead to the accrual of better quality information to inform decisions about appropriate diagnosis and prognosis at both the individual and population levels.

Both the long and short charting forms allow extraction of more information from the data by expanding into subcategories, including information on tooth eruption status, lesion status, and tooth surface area affected; this can give suggestive information about contrasting patterns of the MIH defects among different populations or subset of such. Other tooth abnormalities namely hypoplasia, diffuse opacities, and AI which are clinically identical to MIH may also occur during amelogenesis and can be readily misdiagnosed as MIH. Hence, assigning these defects as present or absent allows their distinction from $\mathrm{MIH}$ and is not timeconsuming as no details about the defects are collected.

It is believed that the inclusion of teeth with less than $1 / 3$ of the crown erupted will not address the problem of the potentially affected, unerupted teeth nor allow full information for the lesion status (Fteita et al. 2006; Muratbegović et al. 2008). More appropriate results, therefore, can be achieved by including teeth with at least $1 / 3$ or more of the crown erupted rather than including only fully erupted teeth, where the latter may result in higher prevalence estimations. Moreover, only defects which are greater than $1 \mathrm{~mm}$ in diameter are recommended to be reported (Lygidakis et al. 2010).

The proposed charting formats can be used in a flexible manner, depending on the investigator's particular requirements. The short charting form provides a "snapshot" of the demarcated enamel defect and the characteristics associated with it by including MIH/HSPM index teeth only in the examination. Even though these are not the only teeth affected but the most frequently involved teeth, further investigation on their distribution in different communities using standardised protocol is required. On the other hand, as the origin of demarcated hypomineralised defects is systemic in nature, the environmental factors which have been postulated as contributing to or causing $\mathrm{MIH} / \mathrm{HSPM}$ may also exist during the maturation process of other teeth developing at different times than the index teeth. This has been denoted earlier by the EAPD committee that FPMs and PIs are not the sole teeth that can be hypomineralised. Accordingly, the long charting form allows examination of the entire dentition that presents at the time of examination in an attempt to give insight about the distribution of MIH/HSPM-like lesions in teeth other than the index teeth. Particularly, if the distribution could be linked to the identification of the predisposing factors, it may allow determination of the aetiological factors of MIH and may assist in implementing strategies to limit its occurrence or even to prevent it.

The extent of the defect by tooth surface area can be a useful measurement tool for severity increment as it reflects defect severity in several ways. For example, it has been reported that the increased extent of the defect area was associated significantly with an increased number of affected FPMs, enamel disintegration, as well as increased carious lesion severity (Ghanim et al. 2011b, 2013b, 2014). Therefore, the proposed method allows assessment for the progressive condition of MIH and thereby the threat to health of the dentition. Furthermore, the charting forms can be used for a range of ages sufficiently wide to determine the prevalence of MIH/HSPM on early and late erupting teeth and changes over time.

Despite caries associated with hypoplasia being widely described in the literature, caries induced by MIH has not been described particularly as a discrete entity (referred to here as atypical caries). There is a growing interpretation that caries risk is the primary incentive for studying $\mathrm{MIH}$, but dental caries has hardly ever been highlighted in a significant majority of the recorded epidemiological studies (Elfrink et al. 2008; Ghanim et al. 2013b). Therefore, simultaneous assessment of dental caries experience with demarcated lesions distribution is encouraged strongly in future research.

Assessment of caries experience is not only required for MIH/HSPM index teeth, but a full mouth assessment is essential. This is in order to minimise the possible confusion in children with severe caries between lost enamelsubstance resulting from hypomineralisation as a primary cause compared to severe caries as a primarycause, so that optimal treatment options can be determined. It is recommended that the International Caries Detection and Assessment System (ICDAS II) for caries diagnosis is used (International Caries Detection and Assessment System (ICDAS II) 2005).

The ICDAS II can provide a detailed description of the caries pattern through categorising carious lesions into stages, allowing a more accurate picture of MIH-caries relationship to be determined. The ICDAS e-learning course is available at "https://www.icdas.org/elearningprogrammes" for training and standardisation exercises on using its scoring criteria and recording sheets. 
The proposed MIH scoring method in its current format has not been validated, nor has reliability testing been assessed nor have data been presented using this method. Whether the objectives of the charting method could be achieved can only be decided from the experience of field testing. Validating and testing the method's reliability have been initiated. Further refinement of the categories is to be undertaken and tested, where applicable to suit specific investigations.

\section{Conclusions}

The use of the proposed scoring method enables the total spectra of MIH to be determined. This is considered an advantage over the use of the current EAPD guidelines and mDDE index individually. The use of the proposed method should be field-tested in different age groups and different countries. Validation of the method and determination of its reliability in different population groups are required.

Acknowledgments The authors would like to acknowledge the generosity of GC Europe and DMG for sponsoring the open access status of this paper - their commitment to support research into MIH is greatly appreciated.

Conflict of interest The authors declare that they have no conflict of interest.

\section{References}

Bagheri R, Ghanim A, Azar M, Manton D. Molar-incisor hypomineralization: discernment of a group of Iranian dental academics. J Oral Health Oral Epidemiol. 2014;3:21-9.

Broadbent JM, Thomson WM, Williams SM. Does caries in primary teeth predict enamel defects in permanent teeth? A longitudinal study. J Dent Res. 2005;84:260-4.

Chawla N, Messer LB, Silva M. Clinical studies in molar-incisorhypomineralisation Part II: development of a severity index. Eur Arch Paediatr Dent. 2008;9:191-9.

Crawford PJM, Aldred M. Bloch-ZA. Amelogenesis imperfecta. Orphanet J Rare Dis. 2007;2:17.

Crombie F, Manton DJ, Kilpatrick N. Molar incisor hypomineralization: a survey of members of the Australian and New Zealand Society of paediatric dentistry. Aust Dent J. 2008;53:160-6.

Elfrink MEC, Schuller AA, Weerheijm KL, Veerkamp JSJ. Hypomineralised second primary molars: prevalence data in Dutch 5-year-olds. Caries Res. 2008;42:282-5.

Elfrink MEC, Ten Cate JM, Jaddoe VW, et al. Deciduous molar hypomineralization and molar incisor hypomineralization. J Den Res. 2012;91:551-5.

Elfrink MEC, Ghanim A, Manton DJ, Weerheijm KL. Standardised studies on molar incisor hypomineralisation (MIH) and hypomineralised second primary molars (HSPM): a need. Eur Arch Paediatr Dent. 2015.

Federation Dentaire International (FDI). Commission on oral health, research and epidemiology. A review of the development defects of enamel index (DDE index. Int Dent J. 1992;42:411-26.
Fteita D, Ali A, Alaluusua S. Molar-incisor hypomineralization $(\mathrm{MIH})$ in a group of school-aged children in Benghazi, Libya. Eur Arch Paediatr Dent. 2006;7:92-5.

Geetha Priya PR, John JB, Elango I. Turner's hypoplasia and nonvitality: a case report of sequelae in permanent tooth. Contemp Clin Dent. 2010;1:251-4.

Ghanim A, Morgan M, Mariño R, Manton D, Bailey D. Perception of molar-incisor hypomineralisation (MIH) by Iraqi dental academics. Int J Paediatr Dent. 2011a;21:261-70.

Ghanim A, Morgan M, Mariño R, Bailey D, Manton D. Molar-incisor hypomineralisation: prevalence and defect characteristics in Iraqi children. Int J Paediatr Dent. 2011b;21:413-21.

Ghanim A, Manton D, Mariño R, Morgan M, Bailey D. Prevalence of demarcated hypomineralisation defects in second primary molars in Iraqi children. Int J Paediatr Dent. 2013a;23:48-55.

Ghanim A, Morgan M, Mariño R, Bailey D, Manton D. An in vivo investigation of salivary properties, enamel hypomineralisation and carious lesion severity in a group of Iraqi school children. Int J Paediatr Dent. 2013b;23:2-12.

Ghanim A, Bagheri R, Golkari A, Manton D. Molar-Incisor Hypomineralisation: a prevalence study amongst primary schoolchildren of Shiraz. Iran. Eur Arch Paediatr Dent. 2014;15:75-82.

Hussein A, Ghanim A, Abu-Hassan M, Manton D. Knowledge, management and perceived barriers to treatment of molar incisor hypomineralisation in general dental practitioners and dental nurses in Malaysia. Eur Arch Paediatr Dent. 2014;15:301-7.

International Caries Detection and Assessment System (ICDAS II). Criteria manual appendix. Workshop held in Baltimore, Maryland, March 12-14th 2005. Available at: http://www.dundee.ac. uk/dhsru/news/icdas.htm. Accessed July 2014.

Jälevik B, Klingberg G. Treatment outcomes and dental anxiety in 18-year-olds with $\mathrm{MIH}$, comparisons with healthy controls-a longitudinal study. Int J Paediatr Dent. 2012;22:85-91.

Kukleva MP, Petrova SG, Kondeva VK, Nihtyanova TI. Molar incisor hypomineralisation in 7-14 years old children in Plovdiv, Bulgaria - an epidemiologic study. Folia Med (Plovdiv). 2008;50:71-5.

Leen A. The interrelationship between molar hypomineralisation and orthodontics. DCD thesis, Melbourne Dental School, The University of Melbourne. 2013.

Leppäniemi A, Lukinmaa PL, Alaluusua S. Non-fluoride hypomineralizations in the first molars and their impact on the treatment need. Caries Res. 2001;35:36-40.

Lo EC, Zheng CG, King NM. Relationship between the presence of demarcated opacities and hypoplasia in permanent teeth and caries in their primary predecessors. Caries Res. 2003;37:456-61.

Lygidakis NA, Wong F, Jälevik B, et al. Best clinical practice guidance for clinicians dealing with children presenting with molar-incisor-hypomineralisation (MIH): an EAPD policy document. Eur Arch Paediatr Dent. 2010;11:75-81.

Mangum JE, Crombie FA, Kilpatrick N, Manton DJ, Hubbard MJ. Surface integrity governs the proteome of hypomineralized enamel. J Den Res. 2010;89:1160-5.

Muratbegović A, Zukanović A, Markovic N. Molar-incisor-hypomineralisation impact on developmental defects of enamel prevalence in a low fluoridated area. Eur Arch Paediatr Dent. 2008;9:228-31.

Oliver K, Messer LB, Manton D, et al. Distribution and severity of molar hypomineralisation: trial of a new severity index. Int $\mathrm{J}$ Paediatr Dent. 2014;24:131-51.

Seow WK. Clinical diagnosis of enamel defects: pitfalls and practical guidelines. Int Dent J. 1997;47:173-82.

Seow WK, Ford D, Kazoullis S, Newman B, Holcombe T. Comparison of enamel defects in the primary and permanent 
dentitions of children from a low-fluoride district in Australia. Pediatr Dent. 2011;33:207-12.

Soviero V, Haubek D, Trindade C, Matta TD, Poulsen S. Prevalence and distribution of demarcated opacities and their sequelae in permanent 1st molars and incisors in 7 to 13-year-old Brazilian children. Acta Odontol Scand. 2009;67:170-5.

Suckling GW, Nelson DG, Patel MJ. Macroscopic and scanning electron microscopic appearance and hardness values of developmental defects in human permanent tooth enamel. Adv Dent Res. 1989;3:219-33.

The $\mathrm{D}_{3} \mathrm{G}$ website. www.thed3group.org. Accessed 11 Mar 2015.

Weerheijm KL, Jälevik B, Alaluusua S. Molar-incisor hypomineralisation. Caries Res. 2001;35:390-1.
Weerheijm K, Duggal M, Mejàre I, et al. Judgement criteria for molar-incisor hypomineralisation (MIH) in epidemiologic studies: a summary of the European meeting on MIH held in Athens, 2003. Eur Arch Paediatr Dent. 2003;4:110-3.

Weerheijm KL, Mejàre I. Molar-incisor-hypomineralisation: a questionnaire inventory of its occurrence in member countries of the European Academy of Paediatric Dentistry (EAPD). Int $\mathrm{J}$ Paediatr Dent. 2003;13:411-6.

Weerheijm KL. Molar incisor hypomineralisation (MIH): clinical presentation, aetiology and management. Dent Update. 2004;31:9-12. 